\title{
Peertechz
}

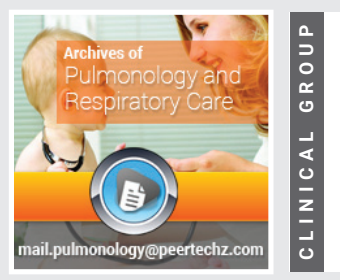

\section{Aspergilloma in post COVID-19 patient}

\section{Arjun Kumar ${ }^{1 *}$, Avishek Layek2 ${ }^{2}$ Rahul Kumar Gupta ${ }^{3}$, Manju Bala ${ }^{1}$ and Akhlesh ${ }^{1}$}

\author{
1Senior Resident, Department of Pulmonary Medicine and Critical Care, All India Institute of Medical \\ Sciences, Rishikesh, 6th Floor, B Block, 249201, India \\ ${ }^{2}$ Junior Resident, Department of Pulmonary Medicine and Critical Care, All India Institute of Medical \\ Sciences, Rishikesh, 6th Floor, B Block, 249201, India
}

${ }^{3}$ DM Resident, Department of Pulmonary Medicine and Critical Care, All India Institute of Medical

Sciences, Rishikesh, 6th Floor, B Block, 249201, India
Received: 15 July, 2021

Accepted: 22 July, 2021

Published: 23 July, 2021

*Corresponding author: Dr. Arjun Kumar, Senior Resident, Department of Pulmonary Medicine and Critical Care, All India Institute of Medical Sciences, Rishikesh, 6th floor, B Block, 249201, India, Tel: :+918054809188; Email: aknlnegi@gmail.com

ORCID: https://orcid.org/0000-0002-5581-6176

Keywords: Monod sign; Aspergilloma; Mycetoma; COVID-19; CT chest

https://www.peertechzpublications.com

\section{Check for updates}

\section{Case}

A 61-year-old male admitted with complaints of increased shortness of breath, right chest pain and blood-tinged sputum expectations for the past 5 days. He was recently treated for COVID-19 infection at home with 6 days of oral corticosteroid and other symptomatic medication. He denied any other significant past medical history. He was recently diagnosed with type 2 diabetes mellitus. He is a chronic smoker and occasionally takes alcohol for the past 25 years. On chest auscultation the rightside air entry was diminished and rest of systemic examination was normal. Routine blood investigation was normal except raised fasting blood sugar levels. His chest radiograph showed right sided mild pneumothorax and right middle zone dense opacity with cavitation Figure 1a. For further evaluation Contrast Computed Tomography (CECT) of thorax with high resolution was done which revealed right sided mild pneumothorax with right-side thick-walled cavity containing polypoidal projection suggestive of fungal ball, mycetoma formation (Monod sign) shown in the Figure 1b. Other differentials are hydatid cyst, pulmonary abscess, bronchogenic carcinoma. For further evaluation sputum for bacterial, fungal, tuberculosis staining and culture were negative. Bronchoalveolar Lavage Fluid (BALF) from the affected bronchial segment sent for further infective analysis of which potassium hydroxide mount $(\mathrm{KOH})$ mount and fungal culture was negative. Serum and BALF beta galactomannan and beta $\mathrm{D}$ glucan were normal. BALF was negative for mycobacterium tuberculosis and other bacterial organisms. So, diagnosis Mycetoma (Aspergilloma) was made on the radiological ground and the patient was started on oral voriconazole tablets 200mg twice daily for

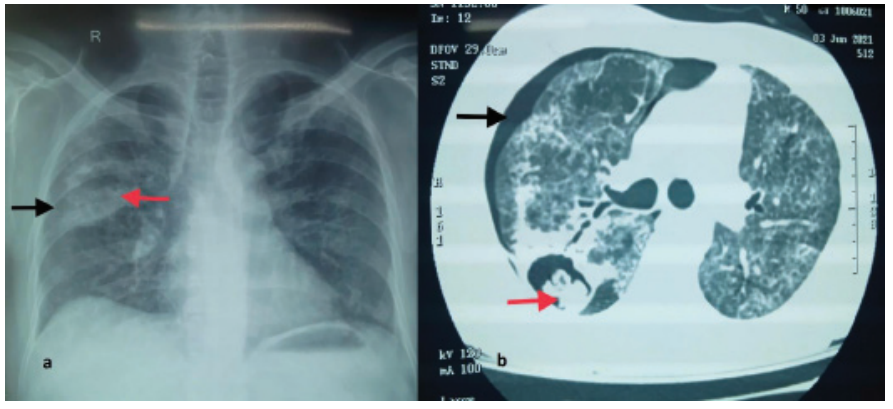

Figure 1: a) C x-ray PA view- Showing right sided mild pneumothorax (black arrow) and cavitation in right middle zone.

b) CECT of thorax axial view- Showing mild pneumothorax (black arrow) and right sided thick walled cavity containing polypoidal projection (red arrow) suggesting fungal ball (Monod sign).

two weeks empirically. Patient's right sided pneumothorax was managed by air aspiration using $16 \mathrm{G}$ cannula and $100 \%$ oxygen inhalation under close monitoring. In view of localised lung cavity, cardiovascular surgical opinion was sought for lobectomy but patient refused for the same; hence patient was advised for close follow up to the outpatient department after 2 weeks of antifungal therapy or anytime if hemoptysis occurs. Patient showed clinico- radiological improvement after six days of antifungal therapy and was discharged home after explaining possible symptoms/ complications related to disease and advised for routine follow up.

\section{Discussion}

Aspergilloma is a fungus ball that mostly grows inside a pre-formed lung cavity lined by ciliated epithelium . 
Aspergillus is a saprophytic filamentous fungus that grows in moist environments in soil, plants, and other debris. Out of all species including Aspergillus niger, A. flavus, and A. oxyzae, Aspergillus fumigatus is the most prevalent human pathogen causing human disease. It's most commonly seen in immunocompromised patients with structural lung disease mostly due to Tuberculosis (TB), bronchiectasis, lung cancer and critically ill patients [1,2]. Risk factors for Aspergillosis include malignancy, stem cell transplant, chemotherapy, neutropenia, prolonged corticosteroid use, primary immunodeficiency syndromes. Patients usually are asymptomatic, but some patients can present with haemoptysis. The severe acute respiratory syndrome Coronavirus 2 (SARS-CoV-2), the aetiological agent of Coronavirus Disease 2019 (COVID-19), has led to a global pandemic defying the geographical borders and putting the lives of billions at risk. The airborne or aerosol transmission occurs via small respiratory droplets or droplet nuclei, less than $10 \mu \mathrm{m}$ in diameter, which remains airborne for sufficient time to transmit the pathogen and may get deposited deep into the respiratory tract, including alveolar region [3]. Once severe acute respiratory syndrome coronavirus 2 (SARSCoV-2) enters the host via contact, droplet or aerosol-mediated transmission [3], the non-specific innate immune response is followed by antigen-specific adaptive immunity mediated by B cells (humoral immunity) producing neutralizing antibodies and $\mathrm{T}$ cells (cellular immunity) including $\mathrm{CD} 8+, \mathrm{CD} 4+$ and regulatory $\mathrm{T}$ cells [4]. Post Covid-19 pneumonia sequelae patients with pulmonary cavitation can also present with aspergilloma especially those with diabetes and treated with prolonged steroids and other immunosuppressive drugs which can further lead to invasive aspergillosis with fatal outcomes. As in this patient he was uncontrolled diabetic and was taking steroids for long time.Further post COVID lung cavities are also reported in few case reports and retrospective analysis which might be a site for development of Aspergilloma in this patient [5]. The transmission of respiratory pathogens have been associated with three primary modes known as "contact," "droplet," and "airborne" transmission.Diagnosis is usually made on chest radiology after excluding the invasive fungal infections. Consistent radiological findings, in association with serological and microbiological evidence of Aspergillus species confirms the diagnosis of Aspergilloman. In our case BALF for fungal culture was negative and the rest of secondary bacterial infections were also negative. Radiology of the chest shows Monod sign which implies a freely mobile (posture dependent) mass (fungal ball) mycetoma most commonly aspergilloma [6]. It should not be confused with the air crescent sign which is seen in recovering Angio invasive aspergillosis [6]. Other radiological sign of invasive aspergillosis is halo sign showing central dense consolidation with surrounding ground glass opacity. Blood and BALF for beta galactomannan antigen (a polysaccharide component of the cell wall) has high specificity for invasive Aspergillosis. The sensitivity of beta galactomannan antigen is higher in bronchoalveolar lavage fluid than serum, although false-positive results are seen in patients concurrently on piperacillin-tazobactam, while false negatives can be seen with high dose steroid therapy or with other non-fumigatus species of aspergillus.In this case both serum and BALF was negative for beta galactomannan as a patient was on long term steroids. The Aspergillus are characterized by 4 to $12 \mathrm{~mm}$ long septate hyphae with dichotomous branching with long conidiophores carrying numerous spores on their tips. Aspergilloma appears as a soft mesh of inflamed, bloated, septate hyphae, fibrin, blood clots, cellular debris, and mucous residues on historical specimens. An immunocompromised patient can get invasive aspergillus infections, while mycetoma is more common in immunocompetent patients with preexisting lung disease. For mild haemoptysis, selective bronchial artery embolization can be life-saving. But surgical resection is the treatment of choice for recurrent haemoptysis. A significant proportion of patients with aspergilloma have a preexisting diseased lung and wedge resection can occasionally be an option for a small, simple mycetoma, anatomical resection of segments or lobes has been the favored approach. As our case was also a candidate for lobectomy but the patient refused for the same, hence we had to continue on medical management. For patients with normal respiratory function, and with aspergilloma involving only one lung, 30-day postoperative mortality is anywhere between 1 to $5 \%$ [7]. Antifungal therapy alone is, on the other hand, of limited benefit in treating either simple or complex aspergilloma [8]. It is utmost important to carefully follow the post COVID-19 recovered patients with chest radiology to prevent the invasive fungal infection and its related complications.

\section{Author contributions}

\section{KA: Collected patient data, drafted manuscript}

\section{LA,4 BM,5A: revised the manuscript}

3. GRK: drafted and revised manuscript

\section{References}

1. Kousha M, Tadi R, Soubani AO (2011) Pulmonary aspergillosis: a clinical review. Eur Respir Rev 20: 156-742. Link: https://bit.ly/3xZ4FqH

2. Iwata H, Sasaki T, Sasamoto M, Miwa T, Hara M, et al. (1988) Aspergilloma in tuberculous cavities. Nihon Kyobu Shikkan Gakkai Zasshi 26: 812-824. Link: https://bit.ly/36TsmVC

3. Priyanka, Choudhary OP, Singh I, Patra G (2020) Aerosol transmission of SARS-CoV-2: The unresolved paradox. Trav Med Infec Dis 37: 101869. Link: https://bit.ly/3fuxQtT

4. Priyanka, Choudhary OP, Singh I (2021) Protective immunity against COVID-19: Unravelling the evidences for humoral vs. cellular components. Travel Med Infect Dis 39: 101911. Link: https://bit.ly/3hHUVMt

5. van Arkel ALE, Rijpstra TA, Belderbos HNA, van Wijngaarden $P$, Verweij $P E$ et al. (2020) COVID-19-associated Pulmonary Aspergillosis. Am J Respir Crit Care Med 202: 132-135. Link: https://bit.ly/3kG2tAz

6. Franquet T, Mullcer NL, Gimenez A, Guembe P, de La Torre J, et al. (2001) Spectrum of pulmonary aspergillosis: histologic, clinical, and radiologic findings. Radiographics 21: 825-837. Link: https://bit.ly/2TqLvLI

7. Badali H, Fakhim H, Zarei F, Nabili M, Vaezi A, et al. (2016) In Vitro Activities of Five Antifungal Drugs Against Opportunistic Agents of Aspergillus Nigri Complex. Mycopathologia 181: 235-240. Link: https://bit.ly/3hV7H9W

8. Gupta PR, Jain S, Kewlani JP (2015) A comparative study of itraconazole in various dose schedules in the treatment of pulmonary aspergilloma in treated patients of pulmonary tuberculosis. Lung India 32: 342-346. Link: https://bit.ly/3hRKOPL

Copyright: (c) 2021 Kumar A, et al. This is an open-access article distributed under the terms of the Creative Commons Attribution License, which permits unrestricted use distribution, and reproduction in any medium, provided the original author and source are credited.

Citation: Kumar A, Layek A, Gupta RK, Bala M, Akhlesh (2021) Aspergilloma in post COVID-19 patient. Arch Pulmonol Respir Care 7(1): 018-019. 